\title{
Performance of a Combined Treatment Approach on the Elimination of Microbes from Poultry Slaughterhouse Wastewater
}

\author{
Kulyash Meiramkulova ${ }^{1}{ }^{(D}$, Aliya Temirbekova ${ }^{1}$ (D) Gulnur Saspugayeva ${ }^{1}$, Assel Kydyrbekova ${ }^{2}$, \\ Davud Devrishov ${ }^{3}$, Zhanar Tulegenova ${ }^{4}$, Karlygash Aubakirova ${ }^{4}$, Nataliya Kovalchuk ${ }^{5}$, Abdilda Meirbekov ${ }^{6}$ \\ and Timoth Mkilima $7, *$ (D)
}

check for updates

Citation: Meiramkulova, K.; Temirbekova, A.; Saspugayeva, G.; Kydyrbekova, A.; Devrishov, D.; Tulegenova, Z.; Aubakirova, K.; Kovalchuk, N.; Meirbekov, A.; Mkilima, T. Performance of a Combined Treatment Approach on the Elimination of Microbes from Poultry Slaughterhouse Wastewater. Sustainability 2021, 13, 3467. https:// doi.org/10.3390/su13063467

Academic Editor: Andreas N. Angelakis

Received: 15 February 2021

Accepted: 18 March 2021

Published: 21 March 2021

Publisher's Note: MDPI stays neutral with regard to jurisdictional claims in published maps and institutional affiliations.

Copyright: (c) 2021 by the authors. Licensee MDPI, Basel, Switzerland. This article is an open access article distributed under the terms and conditions of the Creative Commons Attribution (CC BY) license (https:// creativecommons.org/licenses/by/ $4.0 /)$.
1 Department of Environmental Engineering and Management, Faculty of Natural Sciences, L.N. Gumilyov Eurasian National University, Satpayev Street 2, Nur-Sultan 010000, Kazakhstan; kuleke@gmail.com (K.M.); aliya_090494@mail.ru (A.T.); gulnur_erzhanovna@mail.ru (G.S.)

2 Management Department, Faculty of Economics, L.N. Gumilyov Eurasian National University, Satpayev Street 2, Nur-Sultan 010000, Kazakhstan; asellya@gmail.com

3 Department of Immunology and Biotechnology, Moscow State Academy of Veterinary Medicine and Biotechnology, Scryabin Str. 23, 109472 Moscow, Russia; davud@mgavm.ru

4 Department of Biotechnology, Faculty of Natural Sciences, L.N. Gumilyov Eurasian National University, Satpayev Street 2, Nur-Sultan 010000, Kazakhstan; zhan.ta@mail.ru (Z.T.); karlanasam2015@gmail.com (K.A.)

5 Department of Epizootology, Microbiology, Parasitology and Veterinary and Sanitary Expertise, Krasnoyarsk State Agrarian University, Mir Ave. 90,660049 Krasnoyarsk, Russia; natalkoval55@mail.ru

6 Department of Environment and Chemistry of Khoja Ahmed Yasawi International Kazakh-Turkish University, B.Sattarkhanova Ave. 29, Turkestan 161201, Kazakhstan; abdilda@mail.ru

7 Department of Civil Engineering, Faculty of Architecture and Construction, L.N. Gumilyov Eurasian National University, Satpayev Street 2, Nur-Sultan 010000, Kazakhstan

* Correspondence: tmkilima@gmail.com

Abstract: The efficiency of microbial inactivation in water is highly dependent on the type of treatment technology used as well as the characteristics of the water to be treated. Wastewater from poultry slaughterhouses carries a significant number of microorganisms posing threats to humans and the environment in general. Therefore, the treatment of poultry slaughterhouse wastewater requires the use of appropriate purification systems with high removal efficiency for microbial agents. In this study, the performance of an integrated treatment plant with electrolysis, ultrafiltration, and ultraviolet radiation as the principal treatment units was investigated in terms of microbial inactivation from poultry slaughterhouse wastewater. In this case, total microbial number, total coliform bacteria, thermo-tolerant coliform bacteria, pathogenic flora, including salmonella coliphages, spores of sulfite-reducing clostridia, Pseudomonas aeruginosa, and Staphylococcus aureus and Enterococcus were studied. Approximately $63.95 \%$ to $99.83 \%$ of the microbes were removed by the electrochemical treatment unit as well as a $99.86 \%$ to $100 \%$ removal efficiency was achieved after the combined treatment. However, Pseudomonas aeruginosa was the only microbial agent detected in the final effluent after the combined treatment. The phenomenon suggests that an upgrade to the treatment plant may be required to achieve 100\% removal assurance for Pseudomonas aeruginosa.

Keywords: integrated wastewater treatment; microorganisms; poultry slaughterhouse; electrolysis; ultrafiltration; ultraviolet radiation

\section{Introduction}

The process of slaughtering chickens is associated with the consumption of large quantities of water from the meat processing activities, cleaning of the processing environment, disinfection as well as transportation of the slaughter by-products. The processes also generate large quantities of highly polluted wastewater with organic matter including biological oxygen demand (BOD), chemical oxygen demand (COD), and suspended 
particles [1] as well as pathogenic microorganisms [2], characterized by a high content of proteins, fats, carbohydrates from meat, blood, skin, and feathers. As the population increases around the world, the demand for poultry products has also increased, which in turn affects the general water demand as well as increases the generation of highly polluted wastewater [3]. The rising cost of discharging untreated process water into the local sewage systems, as well as the presence of more restrictive requirements for discharging process water onto surface water [4], has made many poultry farms in the world think of in situ treatment of the wastewater generated from slaughterhouses. Microbes are among the contaminants of significant concern generated from poultry slaughterhouses [5].

Biological contaminants are of different types including different types of bacteria such as fecal coliforms and Escherichia coli [6], Salmonella, Shigella, Vibrio cholerae as well as Pseudomonas aeruginosa [7]. Moreover, some other biological contaminants, such as viruses, fungi as well as diverse parasite cysts and eggs, can be found in the wastewater. The degree to which the biological contaminants may pose threats to environmental and human health is dependent on the type and concentration [8].

There are many health risks associated with exposure to biological contaminants in water including diseases, such as typhoid, cholera, and tuberculosis, caused by bacteria [9], hepatitis caused by viruses [10], as well as dysentery caused by protozoa [11]. Therefore, it is of great importance to ensure that the wastewater from poultry slaughterhouses has been adequately treated to achieve as complete as possible elimination of biological contaminants before either discharge or any other utilization. In general, there are many technologies used for microbial elimination [12-14]; conventional technologies are the most widely used processes for disinfection of water. Chlorine, chlorine dioxide, ozone, and peracetic acid are a few examples of the chemical-based microbial elimination approaches. In addition to chemical disinfectants, ultraviolet (UV) radiation has also been used for many years as a water disinfection technology in the field of wastewater treatment [15]. Also, some other advanced approaches, such as ozonation and membrane filtration [16] as well as electrochemical (EC) methods [17], have been applied to poultry slaughterhouse wastewater treatment. But, the performance of the treatment technologies has also been observed to be affected by the scale and characteristics of wastewater subjected to the treatment process [18]. With the fact that each treatment system is characterized by its advantages and disadvantages in terms of strengths and weaknesses, it is preferable to combine several treatment technologies to form an integrated treatment to achieve higher treatment efficiency for poultry slaughterhouse wastewater [19]. Previous studies have observed that a combination of different technologies has the potential to improve the general performance of a treatment system as pollutants that were not removed by one unit can be removed by the other subsequent units [20]. Electrochemical, ultrafiltration (UF), and UV are among the treatment technologies used in poultry slaughterhouse wastewater treatment. However, the information about their technical feasibility on microbial elimination from poultry slaughterhouse wastewater is still scarce especially when integrated together. Electrochemical treatment systems have been considered cost-effective and highly efficient wastewater treatment technologies. The EC treatment systems have been observed to be highly efficient in the removal of pollutants from poultry slaughterhouse wastewater $[21,22]$. The electrolysis process produces oxidants, such as dissolved oxygen, hydrogen peroxide, hydroxyl, and ozone, that are responsible for the degradation of the outer membrane of the bacterial cell and the destruction of proteins in the cytoplasm, and, finally, the microbial cell death [23]. Despite the EC treatment technologies being extensively studied for recalcitrant organics removal, its application potential towards microbial elimination from wastewater, such as that generated from poultry slaughterhouse processes, is still not well known [24].

Generally, UF is a pressure-driven membrane separation mechanism that removes suspended particulate matter and some dissolved compounds with high molecular weight, including organics and colloids from wastewater [25]. Ultrafiltration is also regarded to be effective in removing bacteria and most viruses present in wastewater [26]. The efficiency 
of UF systems in filtering out microorganisms from wastewater makes the technology ideal for the treatment of poultry slaughterhouse wastewater. Moreover, the UF treatment systems are also useful when applied as pre-treatment units before reverse osmosis, UV, and ozone treatment systems, as disinfection requirements are greatly reduced due to the reduction in suspended solids [27].

Unlike the chemical approaches to water disinfection, UV light has been observed to offer a more rapid and effective inactivation of microorganisms through a physical process $[28,29]$. The UV rays must strike the cell to inactivate microorganisms in water. Ultrafiltration energy breaches the outer cell membrane of the microorganism, of which in the process the DNA is disturbed which, in turn, prevents reproduction [30]. Among the crucial benefits of water treatment with UV is the fact that the treatment process does not alter water chemically as no additional chemicals are added except energy [31]. However, unlike the membrane filtration treatment systems, the sterilized microorganisms with UV rays are not removed from the water. It should also be noted that generally, the UV disinfection process is not primarily designed to remove dissolved organics, inorganics, or any other sort of particles in the water. When the water is subjected to UV rays, the microorganisms exposed to the germicidal wavelengths of UV light are rendered incapable of reproducing and infecting making them harmless [32]. In this study, an integrated lab-scale treatment plant with EC, UF, and UV was studied for its potential application towards microbial elimination from poultry slaughterhouse wastewater.

\section{Materials and Methods}

\subsection{Case study, Sample Collection, and Wastewater Characteristics}

The wastewater samples used in this study were collected from the Izhevsk PC poultry slaughterhouse located in Izhevsk village, Arshalinsky District, in the Akmola Region of the Republic of Kazakhstan, about $70 \mathrm{~km}$ from the capital city Nur-Sultan $\left(51^{\circ} 10^{\prime}\right.$ North latitude and $71^{\circ} 26^{\prime}$ East longitude). The industry has a production capacity of 280 million eggs per year, with a meat production capacity of 3000 tons per year. The poultry products from the poultry farm are daily delivered to the capital city, Nur-Sultan, as well as other cities in Kazakhstan and Russia. The average daily wastewater generated from the production processes is approximately $2.5 \mathrm{~m}^{3} / \mathrm{h}$. Samples were collected and preserved at $4{ }^{\circ} \mathrm{C}$ for transportation to the laboratory. The wastewater samples were treated using the treatment plant installed in the Water and Environmental Management laboratory at the L.N. Gumilyov Eurasian National University in Nur-Sultan, Kazakhstan. Samples were also collected immediately after the EC treatment and analyzed to investigate the performance of the EC treatment unit in terms of microbial inactivation. Table 1 highlights the general characteristics of the wastewater in terms of microbial contaminants. A total of nine (9) microbial parameters (total microbial number (TMN), total coliform bacteria (TCB), thermo-tolerant coliform bacteria (TTCB), pathogenic flora, including salmonella coliphages, spores of sulfite-reducing clostridia, Pseudomonas aeruginosa, Staphylococcus aureus, and Enterococcus) were studied. The recommended guidelines presented in Table 1 are based on the standards set by the government of Kazakhstan for household water supply.

\subsection{Experimental Setup}

The treatment plant was composed of EC, UF, and UV as the main treatment units installed in series. Each experimental session used 1.7 L of wastewater. The experiments started by treating the wastewater samples from defeathering and cooling sections of the slaughterhouse separately followed by the experiments from the mixed wastewater. The main treatment process started from the EC unit by applying a unipolar voltage to the metal plates-electrodes from the power unit. The effluent from the EC unit was then subjected to the UF treatment process, preparing the wastewater for UV disinfection. 
Table 1. Wastewater characteristics (number of samples $=12$ ).

\begin{tabular}{ccccccc}
\hline Microorganisms & Min & Max & M & Median & SD & Guideline \\
\hline TMN & 1254 & 2305 & 1780 & 1780 & 429.07 & $<50 \mathrm{CFU}$ in $1 \mathrm{~mL}$ \\
TCB & 1122 & 2450 & 1991 & 2400 & 614.58 & No CFU in $100 \mathrm{~mL}$ \\
TTCB & 659 & 1020 & 793 & 700 & 161.38 & No CFU in $100 \mathrm{~mL}$ \\
$\begin{array}{c}\text { Pathogenic flora, } \\
\text { including salmonella }\end{array}$ & 55 & 93 & 78 & 85 & 16.36 & No CFU in $1000 \mathrm{~mL}$ \\
Coli phages & 30 & 48 & 37 & 32 & 8.06 & No CFU in $100 \mathrm{~mL}$ \\
Spores of sulfite-reducing clostridia & 53 & 90 & 71 & 70 & 15.12 & No CFU in $20 \mathrm{~mL}$ \\
Pseudomonas aeruginosa & 2500 & 4020 & 3197 & 3070 & 626.97 & No CFU in $100 \mathrm{~mL}$ \\
Staphylococcus aureus & 2030 & 3987 & 2935.67 & 2790 & 805.55 & No CFU in $100 \mathrm{~mL}$ \\
Enterococcus & 1022 & 2090 & 1396.67 & 1078 & 490.79 & No CFU in $100 \mathrm{~mL}$ \\
\hline
\end{tabular}

$\mathrm{CFU}=$ colony forming unit; $\mathrm{TMN}$ in $\mathrm{CFU} / \mathrm{mL}$, all other parameters in $\mathrm{CFU} / 100 \mathrm{~mL}$; Min = minimum, Max $=$ maximum, $\mathrm{M}=$ mean, $\mathrm{SD}=$ standard deviation, $\mathrm{TMN}=$ total microbial number, $\mathrm{TCB}=$ total coliform bacteria, $\mathrm{TTCB}=$ thermo-tolerant coliform bacteria .

\subsubsection{EC Treatment}

The EC treatment process was done in a container with $15 \times 13 \times 11 \mathrm{~cm}^{3}$ dimensions made of polypropylene material in which the electrodes were placed. Direct current in a potentiostatic mode was applied to both electrodes in the EC container, with a design power supply ranging from 0 to $50 \mathrm{~V}$ for the voltage and 0 to $10 \mathrm{~A}$ for the current (Xinhua Electrical Weld Company, Loudi City, China). In this study, aluminum was used as an anode electrode with dimensions of $10.8 \times 11.8 \times 0.2 \mathrm{~cm}^{3}$, while titanium was used as a cathode electrode with dimensions of $10.8 \times 11.8 \times 0.7 \mathrm{~cm}^{3}$. To avoid variability, the distance between the electrodes was fixed to $2 \mathrm{~cm}$ in all sessions of the experiments and were placed parallel to the reactor. The hydraulic retention time was selected following observations from previous studies. The other general technical specifications are summarized in Table 2.

Table 2. Electrochemical (EC) technical specifications.

\begin{tabular}{ccc}
\hline Parameter & Value & Unit \\
\hline Initial water temperature & $5-10$ & ${ }^{\circ} \mathrm{C}$ \\
Potential (voltage) & 24 & $\mathrm{~V}$ \\
Average current & 5.5 & $\mathrm{~A}$ \\
Average power & 132 & $\mathrm{~W}$ \\
Hydraulic retention time & 40 & $\mathrm{~min}$ \\
\hline
\end{tabular}

\subsubsection{Ultrafiltration}

The treatment process is followed by the mechanical hollow module UF which plays an important role in preparing the pre-treated wastewater for UV disinfection. In this process, some of the particles that managed to pass from the previous treatment units are removed. The UF treatment process is achieved by passing the effluent from the EC unit through a cartridge-type filter for ultrafine cleaning. The transboundary pressure for the water to flow through the filter material (polypropylene) with a pore size of $0.02 \mu \mathrm{m}$ or 1760 kilo-Daltons (Aquafor LLP, Moscow, Russia) is generated by the NS1 pump (Pionerskaya str 27A, Saint Petersburg, Russia) installed within the UF compartment. Table 3 provides a general summary of the technical specifications from the UF treatment unit.

Table 3. Ultrafiltration (UF) technical specifications.

\begin{tabular}{ccc}
\hline Parameter & Unit & Value \\
\hline Filter pore size & $\mu \mathrm{m}$ & 0.02 \\
Module diameter & $\mathrm{mm}$ & 5 \\
Module length & $\mathrm{cm}$ & 30 \\
Pump supply voltage & $\mathrm{V}$ & 24 \\
Pump power & $\mathrm{Kw}$ & $0.2-0.4$ \\
\hline
\end{tabular}




\subsubsection{UV Disinfection}

After the treatment processes from the EC and UF units, the wastewater was subjected to the UV disinfection unit to eliminate the remaining microorganisms. The basic principle of this UV sterilization is that water is exposed to UV radiation to inactivate microbes in the water. The UV sterilizer was installed within a cylindrical container made of stainless steel equipped with input and output nozzles. Inside the container sealed with a plastic knob, there was a quartz tube mounted with a quartz germicidal lamp installed inside. The general purpose of the quartz tube is to avoid direct water contact with the lamp and for easy replacement without the need to drain liquid from the UV container. The UV sterilization unit was properly designed to sustain water pressure during the purification process. Valves were also installed to control and adjust the flow of water during the treatment process. More technical specifications for the UV treatment unit are presented in Table 4 . Figure 1 presents the lab installation and schematic diagram of the UV disinfection unit.

Table 4. UV technical specifications.

\begin{tabular}{ccc}
\hline Parameter & Unit & Value \\
\hline Power & $\mathrm{W}$ & 40 \\
Flow rate & $\mathrm{L} / \mathrm{s}$ & 0.69 \\
Radiation dose & $\mathrm{mJ} / \mathrm{cm}^{2}$ & 60 \\
Operating pressure & $\mathrm{bar}$ & 8 \\
Supply voltage & $\mathrm{V}$ & 220 \\
Retention time & $\mathrm{min}$ & 24 \\
\hline
\end{tabular}

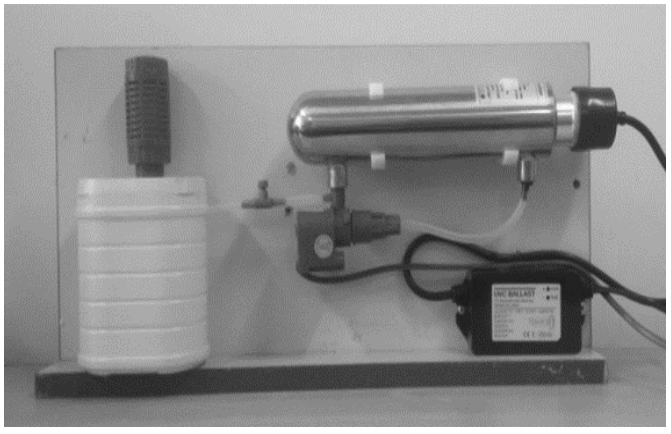

(a)

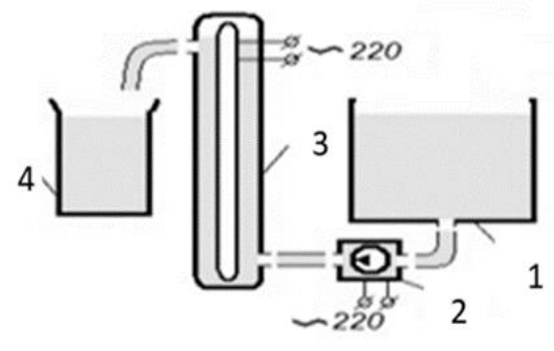

(b)

Figure 1. Photochemical treatment system. (a) Lab-installed UV disinfection unit. (b) Schematic diagram: 1-wastewater reservoir, 2-small pump, 3-UV sterilizer, 4-purified water reservoir.

\subsection{Analytical Methods}

The microbial analysis was achieved using the membrane filtration method [33], where the water samples before and after the treatment processes were passed through a membrane filter with a pore size of $0.45 \mu \mathrm{m}$ and then incubated on an agar plate at $37^{\circ} \mathrm{C}$ for $48 \mathrm{~h}$ (except thermotolerant coliform bacteria at $44^{\circ} \mathrm{C}$ ). The grown colonies of microorganisms were cultured on the appropriate selective media: nutrient agar, Endoagar, azide agar, cetrimide agar, and bismuth-sulfite agar. To detect coliphages in the water samples, the accumulation method of coliphages in the enrichment medium on E. coli K12 Str.R. test culture was used. In the nutrient agar of double concentration, melted and cooled to $45-49^{\circ} \mathrm{C}$, E. coli wash was added at a rate of $2.0 \mathrm{~mL}$ of wash for every $100 \mathrm{~mL}$ of agar. The water samples were heated to $35-44{ }^{\circ} \mathrm{C}$ and immediately (no more than 5 min after reaching the required temperature) poured into 5 Petri dishes and immediately $20 \mathrm{~mL}$ of agar mixture with E. coli culture was added to each cup. Cups with frozen agar were placed bottom-up in a thermostat and incubated. Iron-sulfite agar under conditions close to anaerobic was used for the analysis of the spores of sulfite-reducing clostridium. 
In general, the microbial analysis of the water samples was accomplished following the recommendations in the American Public Health Association (APHA), "Standard Methods for the Examination of Water and Wastewater" [34].

\subsection{Statistical Methods}

The results from the microbial analysis were subjected to statistical analysis for an easy interpretation of the results. The statistical analysis included computation of removal efficiencies for each of the studied microbial parameters. The removal efficiencies were computed in terms of the percent reduction in Equation (1) and log reduction in Equation (2), to investigate the performance of the treatment approach with respect to the studied microbial parameters. Both percent reduction and log reduction were computed using average CFU values. The approach used for the treatment efficiency analysis is summarized in Equations (1) and (2).

$$
T_{e}(\%)=\frac{C_{b}-C_{a}}{C_{b}} \times 100 \%
$$

where $T_{e}$ is percent reduction, $C_{b}$ is the number of viable microorganisms before treatment, and $C_{b}$ is the number of viable microorganisms after treatment.

$$
\text { Log reduction }=\log _{10}\left(\frac{C_{b}}{C_{b}}\right)
$$

\section{Results and Discussion}

The wastewater samples treated using the combination of EC, UF, and UV were analyzed. Tables 5 and 6 provide a summary of the microbial analysis results presented in terms of minimum values (Min), maximum (Max), arithmetic mean (AM), median, standard deviation (SD), as well as log reduction value (LRV).

Table 5. Microbial results from EC effluent (number of samples =12).

\begin{tabular}{ccccccc}
\hline Microbial Parameter & Min & Max & M & Median & SD & LRV \\
\hline TMN & 34 & 100 & 62 & 50 & 28.11 & 1 \\
TCB & 0 & 36 & 20 & 23 & 14.88 & 2 \\
TTCB & 0 & 87 & 29 & 0 & 41.01 & 1 \\
Pathogenic flora, & 0 & 84 & 28 & 0 & 39.60 & 0 \\
including salmonella & 0 & 2 & 1 & 0 & 0.94 & 1 \\
Coliphages & 2 & 5 & 4 & 4 & 1.25 & 1 \\
Spores of sulfite-reducing clostridia & 20 & 46 & 31 & 25 & 11.26 & 2 \\
Pseudomonas aeruginosa & 0 & 16 & 6 & 1 & 7.32 & 2 \\
Staphylococcus aureus & 0 & 4 & 3 & 3 & 1.70 & 2 \\
Enterococcus & & & & &
\end{tabular}

$\mathrm{TMN}$ in $\mathrm{CFU} / \mathrm{mL}$, all other parameters in CFU/100 mL.

Figure 2 shows the trend of microbial concentrations in the raw wastewater for the case of TMN and TCB from the defeathering and cooling wastewater samples. From Figure 2a, it can be observed that the TMN concentration in the defeathering wastewater had a more symmetric distribution with the median observed to be closer to the middle. That means, from the list of experiments, most of the concentration values from the counted microbes were around $1400 \mathrm{CFU} / 100 \mathrm{~mL}$. The boxplot from the cooling section wastewater samples shows the median closer to the upper or top quartile; in that matter, the distribution of microbial concentration in the studied wastewater samples is considered to be "negatively skewed", with concentration values ranging from 500 to $1500 \mathrm{CFU} / 100 \mathrm{~mL}$. 
Table 6. Microbial results from the final effluent (number of samples $=12$ ).

\begin{tabular}{cccccc}
\hline Microbial Parameter & Min & Max & M & Median & SD \\
\hline TMN & 0 & 0 & 0 & 0 & 0 \\
TCB & 0 & 0 & 0 & & 0 \\
TTCB & 0 & 0 & 0 & 0 & 0 \\
Pathogenic flora, including salmonella & 0 & 0 & 0 & 0 & 0 \\
Coli phages & 0 & 0 & 0 & 0 & 0 \\
Spores of sulfite-reducing clostridia & 0 & 0 & 0 & 0 & 0 \\
Pseudomonas aeruginosa & 0 & 13 & 5 & 0 & 6.13 \\
Staphylococcus aureus & 0 & 0 & 0 & 0 & 0 \\
Enterococcus & 0 & 0 & 0 & 0 & 0 \\
\hline
\end{tabular}

$\mathrm{TMN}$ in CFU/mL, all other parameters in CFU/100 mL.
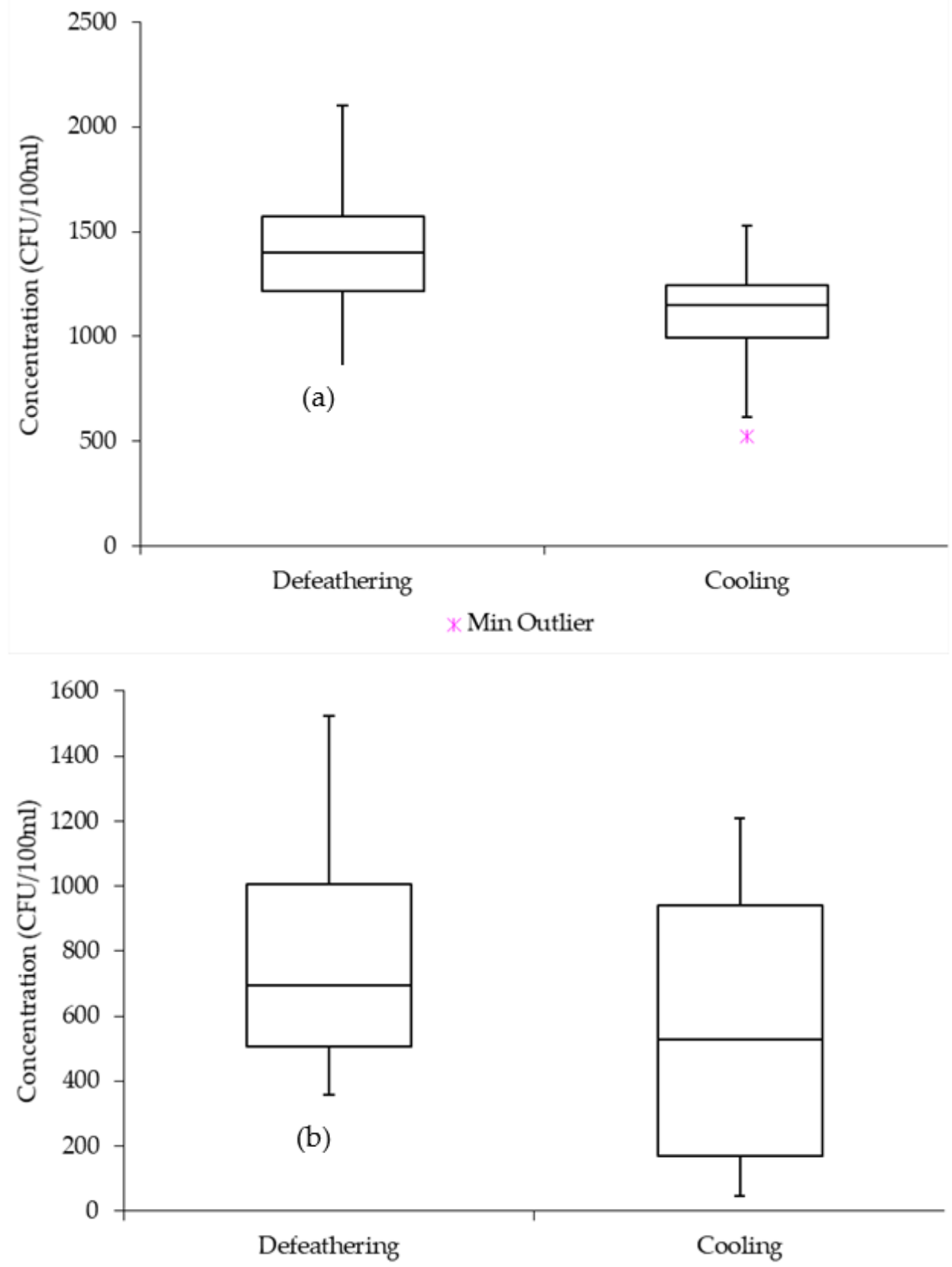

Figure 2. Microbial concentrations from defeathering and cooling sources: (a) TMN in raw wastewater; (b) TCB in raw wastewater. 
From the Figure $2 \mathrm{~b}$ defeathering boxplot, the median was observed to be closer to the lower quartile with an indication that the TCB concentration data from the studied wastewater samples constitute a higher frequency of more high concentration values than the low concentration values ("positively skewed"), with most of the concentration values being below $800 \mathrm{CFU} / 100 \mathrm{~mL}$. While that of the cooling section observed to be symmetric, with concentration values ranging from 40 to $1200 \mathrm{CFU} / 100 \mathrm{~mL}$. Moreover, the boxplots show a significant variation in terms of microbe concentrations in the raw wastewater. Therefore, a relatively stable treatment system is of significant necessity to achieve a high-quality effluent from such a fluctuating flow in terms of pollution loading.

In general, Figure 2 reveals further that the wastewater from the defeathering section is more contaminated with microbes than the wastewater from the cooling section of the poultry slaughterhouse. The phenomenon can be highly linked to the nature of production activities between the two sections, of which the defeathering process is regarded to be generating wastewater with a higher organic load than the cooling wastewater [35].

Both TMN and TCB were the main microbial parameters investigated when the wastewater samples from defeathering and cooling sections of the slaughterhouse were treated separately. In general, the integrated treatment plant achieved more than $99.83 \%$ of microbial removal efficiency from both defeathering and cooling wastewater samples. The difference in terms of removal efficiency for TMN and TCB from both defeathering and cooling sources is literary small (defeathering: $99.86 \%$ removal efficiency from TMN and 99.97\% from TCB, cooling: 100\% removal efficiency from TMN and 99.83\% from TCB). The results indicate that the treatment approach can be highly effective even when subjected to wastewater with fluctuating pollution load. The impressive performance can be highly linked to the fact that each unit within the integrated plant has some degree of microbial elimination capacity. For instance, during the electrolysis process, microbes are killed by a variety of oxidants that are produced within the process [36], as well as the UF treatment process can retain some of the microorganisms depending on the filter pore size [37]. While, the UV disinfection technology was used in this study specifically for the elimination of microbes in the pre-treated water.

\subsection{EC Effluent Quality}

From Table 5, it can be observed that in some cases the EC treatment unit was able to eliminate all the microbes in wastewater with a zero (0) microbial count being achieved as the minimum concentration value for TCB, TTCB, pathogenic flora, including salmonella, coli phages, Staphylococcus aureus as well as Enterococcus. In general, the lowest average concentration value from the EC effluent was observed from the coli phages achieving $1 \mathrm{CFU} / 1000 \mathrm{~mL}$. However, it should also be noted that the concentration of coli phages was observed to be generally low in raw wastewater. Moreover, the EC treatment unit faced a significant challenge in the removal of pathogenic flora, including salmonella. The average concentration of pathogenic flora, including salmonella, was $78 \mathrm{CFU} / 100 \mathrm{~mL}$ in the raw wastewater, while the EC treatment unit was able to reduce the concentration to $28 \mathrm{CFU} / 100 \mathrm{~mL}$, which can be termed as low performance in comparison to the other studied microbial parameters. The EC current and electrode (anode) potential are among the important parameters that have the most influence on the production rate of strong oxidants responsible for microbe elimination [38]. In that matter, adjustments to the EC current may significantly improve the performance of the treatment unit in terms of microbial elimination. Also, based on the LRVs (see Table 4), the EC treatment unit achieved two as the maximum LRV (from TCB, Pseudomonas aeruginosa, Staphylococcus aureus, and Enterococcus) which is equivalent to approximately $99 \%$ removal efficiency, with 0 LRV observed from pathogenic flora, including salmonella, indicating less than $90 \%$ removal efficiency.

\subsection{Final Effluent Quality}

From Table 6, it can be observed that after the combined treatment, the treatment plant was able to eliminate all the microbes in the wastewater for all the studied microbial 
parameters, except Pseudomonas aeruginosa. For Pseudomonas aeruginosa, the treatment plant did not achieve 0 CFU / $100 \mathrm{~mL}$ during some experimental sessions, and the microbial parameter was generally observed to be the most resistant group among the studied microbial parameters. On average, a microbial count of 5 CFU/100 mL for Pseudomonas aeruginosa was recorded in the final effluent after the combined treatment. The maximum recorded Pseudomonas aeruginosa microbial count was 13 CFU/100 mL. However, in some experiments, the treatment approach achieved 0 CFU/100 mL for Pseudomonas aeruginosa as observed in Table 6.

In general, despite the challenge with Pseudomonas aeruginosa, the treatment approach was able to achieve $0 \mathrm{CFU} / 100 \mathrm{~mL}$ as the minimum recorded concentration value for all the studied microbial parameters after $40 \mathrm{~min}$ of retention and an average of $5.5 \mathrm{~A}$ from the EC treatment unit as well as a combination of $60 \mathrm{~mJ} / \mathrm{cm}^{2}$ radiation dose and 24 min retention time from UV unit. That means, in the list of the experiments at least one experiment observed the treatment plant inactivating all the microbes in the wastewater. The phenomenon indicates that depending on the characteristics of the wastewater, the treatment approach can be able to eliminate the microbes to $0 \mathrm{CFU} / 100 \mathrm{~mL}$.

\subsection{General Removal Efficiency}

From Figure 3, it can be observed that in terms of the removal efficiency, the EC treatment unit was able to remove the majority of the microorganisms with an efficiency ranging from $64.1 \%$ to $99.83 \%$. In the raw wastewater, an average of $1780 \mathrm{CFU} / \mathrm{mL}$ of TMN was recorded, after the EC treatment, an average of $62 \mathrm{CFU} / \mathrm{mL}$ was recorded which is equivalent to $96.52 \%$ removal efficiency. For the TCB, an average of $1991 \mathrm{CFU} / 100 \mathrm{~mL}$ was recorded in the raw wastewater, with $20 \mathrm{CFU} / 100 \mathrm{~mL}$ recorded as an average count after the EC treatment which is equivalent to $99 \%$ removal efficiency. Moreover, an average of $793 \mathrm{CFU} / 100 \mathrm{~mL}$ of TTCB was recorded in the raw wastewater, while after the EC treatment an average count of $29 \mathrm{CFU} / 100 \mathrm{~mL}$ was recorded, equivalent to $96.34 \%$ removal efficiency. An average of $78 \mathrm{CFU} / 100 \mathrm{~mL}$ of pathogenic flora, including salmonella was recorded from the raw wastewater, while an average of $28 \mathrm{CFU} / 100 \mathrm{~mL}$ of pathogenic flora, including salmonella, was recorded after the EC treatment, equivalent to a $64.1 \%$ removal efficiency.

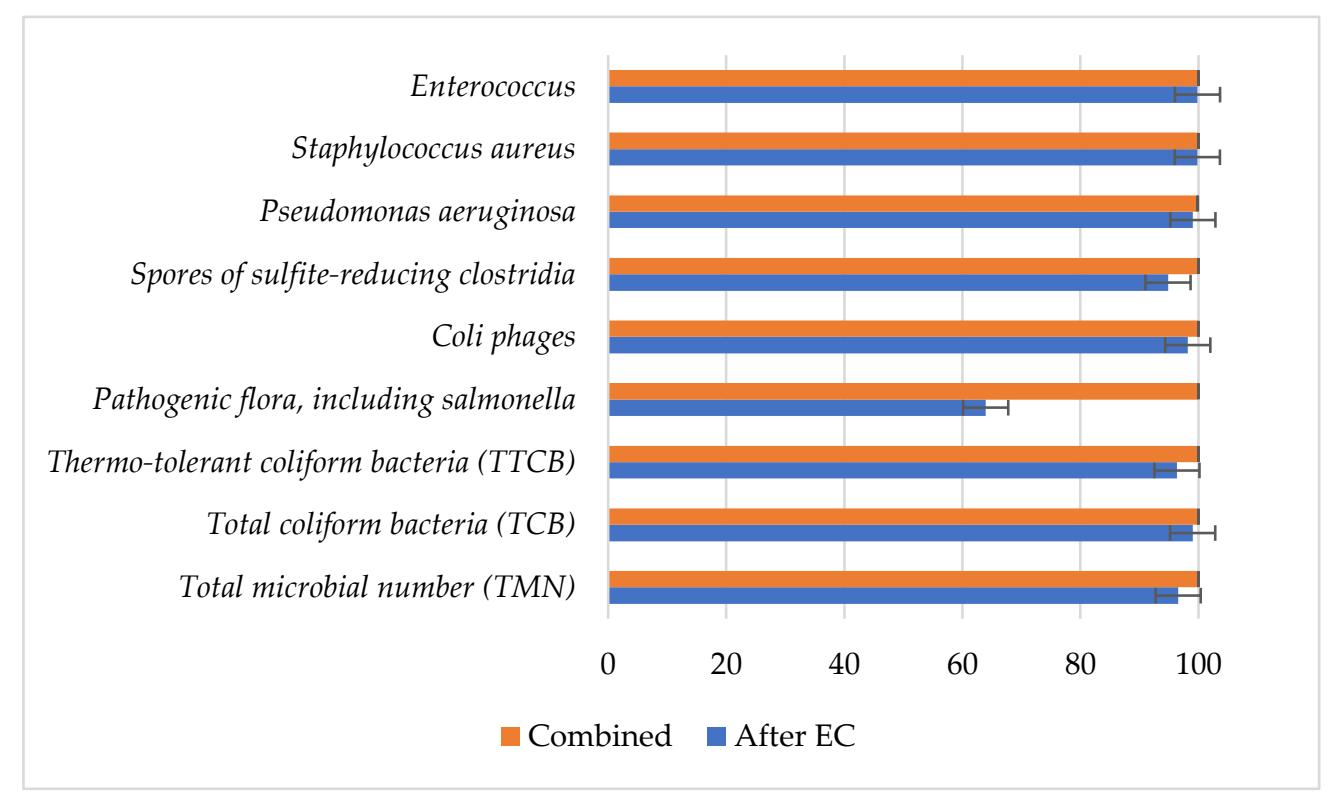

Figure 3. Microbes removal efficiency from EC and combined treatment (final) effluents.

From the combined treatment, the treatment plant achieved almost a $100 \%$ removal efficiency for all the studied microbial parameters, except for Pseudomonas aeruginosa of which an average of $99.84 \%$ removal efficiency was achieved. According to the literature [39-41], 
the high removal resistance observed from the Pseudomonas aeruginosa can be highly linked to the ability of the bacteria to form a biofilm as observed from the UV lamp fouling, which is a consortium of bacteria embedded in a self-produced polymer matrix composed of protein, polysaccharide, and DNA. In general, bacteria associated with biofilms are much more difficult to kill and remove [42]. Pseudomonas aeruginosa is highly resistant to disinfectants as well as antibiotics and is considered as one of the most problematic bacteria in healthcare facilities and is responsible for approximately $10-20 \%$ of hospital-associated infections [43]. The bacterium is naturally resistant to many antibiotics and disinfectants as a result of the permeability barrier from its Gram-negative outer membrane. Once the biofilms are formed, they are difficult to remove because the extracellular polymeric substance (EPS) is firmly attached to the surface and can block access of antimicrobial agents to individual cells, leaving behind a source for recontamination [44]. In general, Pseudomonas aeruginosa is referred to as one of the most problematic bacteria [43]. Chronic infections are among the significant concerns of bacterial biofilms, as they are characterized by high tolerance to antibiotics and disinfectants as well as resisting phagocytosis and other components of the human body's defense system [45].

Although the general lowest removal efficiency $(99.84 \%)$ from the final effluent was observed from the Pseudomonas aeruginosa microbial count, the EC treatment unit was able to lower the count from an average of 3197 to $31 \mathrm{CFU} / 100 \mathrm{~mL}$, which is equivalent to $99 \%$ removal efficiency. This means the combination of UF and UV radiation did not seem to be that effective for the elimination of Pseudomonas aeruginosa.

\section{Conclusions}

The applicability potential of an integrated treatment plant with EC, UF, and UV radiation for microbial elimination from poultry slaughterhouse wastewater was studied. From the analysis results, it was observed that the EC treatment unit was able to remove the majority of the microorganisms with efficiency ranging from $63.95 \%$ to $99.83 \%$. While on average $100 \%$ removal efficiency was achieved from most of the studied microbial parameters after the combined treatment at an average current of $5.5 \mathrm{~A}$ and 40 min retention from the EC treatment unit as well as $60 \mathrm{~mJ} / \mathrm{cm}^{2}$ radiation dose and $24 \mathrm{~min}$ retention time from the UV treatment unit, with the exception of Pseudomonas aeruginosa which was still detected in the final effluent of some of the experimental sessions. Furthermore, the study observed that the EC treatment unit was more effective in the inactivation of Pseudomonas aeruginosa than the combination of UF and UV. In that matter, to eliminate the highly resistant microbial parameter, some upgrades to the treatment plant, such as a general increase in the hydraulic retention time especially for the EC treatment unit, would be required. It is of significant interest in the future to investigate the optimal conditions for 100\% elimination of Pseudomonas aeruginosa from the poultry slaughterhouse wastewater. This study revealed further the potential of combining EC, UF, and UV radiation for a high-efficiency microbial elimination from poultry slaughterhouse wastewater and other types of wastewater.

Author Contributions: Conceptualization, K.M.; methodology, K.M. and T.M.; software, A.T. and A.K.; validation, G.S., D.D., Z.T., K.A., N.K. and A.M.; formal analysis, T.M.; investigation, K.M., A.T., T.M., A.K., G.S., Z.T. and K.A.; resources, K.M., D.D., N.K., A.M.; data curation, K.M. and T.M.; writing — original draft preparation, T.M.; writing—review and editing, K.M., A.T., A.K., G.S., Z.T. and T.M.; visualization, K.A., K.M., N.K. and T.M.; supervision, K.M; project administration, K.M; funding acquisition, K.M. All authors have read and agreed to the published version of the manuscript.

Funding: This research was funded by the Ministry of Education and Science, the Republic of Kazakhstan in support of the project titled, "Reducing the Technogenic Impact on Water Resources with Using Water Recycling Technology", No. BR05236844/215, 2018-2020.

Institutional Review Board Statement: Not applicable.

Informed Consent Statement: Not applicable. 


\section{Data Availability Statement: Not applicable.}

Conflicts of Interest: The authors declare no conflict of interest. The funders had no role in the design of the study; in the collection, analyses, or interpretation of data; in the writing of the manuscript, or in the decision to publish the results.

\section{References}

1. Avula, R.Y.; Nelson, H.M.; Singh, R.K. Recycling of poultry process wastewater by ultrafiltration. Innov. Food Sci. Emerg. Technol. 2009, 10, 1-8. [CrossRef]

2. Dlangamandla, C.; Dyantyi, S.A.; Mpentshu, Y.P.; Ntwampe, S.K.O.; Basitere, M. Optimisation of bioflocculant production by a biofilm forming microorganism from poultry slaughterhouse wastewater for use in poultry wastewater treatment. Water Sci. Technol. 2016, 73, 1963-1968. [CrossRef]

3. Mottet, A.; Tempio, G. Global poultry production: Current state and future outlook and challenges. World's Poult. Sci. J. 2017, 73, 245-256. [CrossRef]

4. Feng, X.; Chu, K.H. Cost optimization of industrial wastewater reuse systems. Process Saf. Environ. Prot. 2004, 82, 249-255. [CrossRef]

5. Zarei, A.; Biglari, H.; Mobini, M.; Dargahi, A.; Ebrahimzadeh, G.; Narooie, M.; Mehrizi, E.; Yari, A.; Mohammadi, M.J.; Baneshi, M.M.; et al. Disinfecting Poultry Slaughterhouse Wastewater Using Copper Electrodes in the Electrocoagulation Process. Pol. J. Environ. Stud. 2018, 27, 1907-1912. [CrossRef]

6. Pachepsky, Y.A.; Shelton, D.R. Escherichia coli and fecal coliforms in freshwater and estuarine sediments. Crit. Rev. Environ. Sci. Technol. 2011, 41, 1067-1110. [CrossRef]

7. Shannon, K.E.; Lee, D.-Y.; Trevors, J.T.; Beaudette, L.A. Application of real-time quantitative PCR for the detection of selected bacterial pathogens during municipal wastewater treatment. Sci. Total Environ. 2007, 382, 121-129. [CrossRef] [PubMed]

8. Schweitzer, L.; Noblet, J. Water Contamination and Pollution. In Green Chemistry: An Inclusive Approach; Elsevier Science: Boston, MA, USA, 2018; ISBN 9780128095492.

9. Coulliette, A.D.; Enger, K.S.; Weir, M.H.; Rose, J.B. Risk reduction assessment of waterborne Salmonella and Vibrio by a chlorine contact disinfectant point-of-use device. Int. J. Hyg. Environ. Health 2013, 216, 355-361. [CrossRef] [PubMed]

10. El-Kamary, S.S.; Strickland, G.T. Hepatitis, Viral. In International Encyclopedia of Public Health; Academic Press: Cambridge, MA, USA, 2016; ISBN 9780128037089.

11. Kelly, P. Intestinal protozoa. In Clinical Infectious Disease; Schlossberg, D., Ed.; Cambridge University Press: Cambridge, UK, 2015; pp. 1313-1317, ISBN 9781139855952.

12. Richardson, S. Disinfection by-products and other emerging contaminants in drinking water. TrAC Trends Anal. Chem. 2003, 22, 666-684. [CrossRef]

13. Malato, S.; Fernández-Ibáñez, P.; Maldonado, M.I.; Blanco, J.; Gernjak, W. Decontamination and disinfection of water by solar photocatalysis: Recent overview and trends. Catal. Today 2009, 147, 1-59. [CrossRef]

14. Robertson, P.K.J.; Robertson, J.M.C.; Bahnemann, D.W. Removal of microorganisms and their chemical metabolites from water using semiconductor photocatalysis. J. Hazard. Mater. 2012, 211-212, 161-171. [CrossRef] [PubMed]

15. Collivignarelli, M.; Abbà, A.; Benigna, I.; Sorlini, S.; Torretta, V. Overview of the Main Disinfection Processes for Wastewater and Drinking Water Treatment Plants. Sustainability 2017, 10, 86. [CrossRef]

16. Advanced Wastewater Disinfection Technologies: State of the Art and Perspectives. Water Sci. Technol. 1999, 40, 203-213. [CrossRef]

17. Meiramkulova, K.; Jakupova, Z.; Orynbekov, D.; Tashenov, E.; Kydyrbekova, A.; Mkilima, T.; Inglezakis, V.J. Evaluation of Electrochemical Methods for Poultry Slaughterhouse Wastewater Treatment. Sustainability 2020, 12, 5110. [CrossRef]

18. Meiramkulova, K.; Zorpas, A.A.; Orynbekov, D.; Zhumagulov, M.; Saspugayeva, G.; Kydyrbekova, A.; Mkilima, T.; Inglezakis, V.J. The Effect of Scale on the Performance of an Integrated Poultry Slaughterhouse Wastewater Treatment Process. Sustainability 2020, 12, 4679. [CrossRef]

19. De Nardi, I.R.; Del Nery, V.; Amorim, A.K.B.; dos Santos, N.G.; Chimenes, F. Performances of SBR, chemical-DAF and UV disinfection for poultry slaughterhouse wastewater reclamation. Desalination 2011, 269, 184-189. [CrossRef]

20. Latif, M.A.; Ghufran, R.; Wahid, Z.A.; Ahmad, A. Integrated application of upflow anaerobic sludge blanket reactor for the treatment of wastewaters. Water Res. 2011, 45, 4683-4699. [CrossRef]

21. Meiramkulova, K.; Devrishov, D.; Marzanov, N.; Marzanova, S.; Kydyrbekova, A.; Uryumtseva, T.; Tastanova, L.; Mkilima, T. Performance of Graphite and Titanium as Cathode Electrode Materials on Poultry Slaughterhouse Wastewater Treatment. Materials 2020, 13, 4489. [CrossRef]

22. Bayar, S.; Yıldız, Y.Ş.; Yılmaz, A.E.; İrdemez, Ş. The effect of stirring speed and current density on removal efficiency of poultry slaughterhouse wastewater by electrocoagulation method. Desalination 2011, 280, 103-107. [CrossRef]

23. Khosravi, A.; Honarmand rad, Z.; Amirmahani, N.; Nasiri, A.; Malakootian, M. The Application of Electrolysis Method to Disinfect Water Contaminated by Salmonella and Shigella. J. Water Chem. Technol. 2019, 41, 182-187. [CrossRef]

24. Zhou, S.; Huang, S.; Li, X.; Angelidaki, I.; Zhang, Y. Microbial electrolytic disinfection process for highly efficient Escherichia coli inactivation. Chem. Eng. J. 2018, 342, 220-227. [CrossRef]

25. Van Der Bruggen, B.; Vandecasteele, C.; Van Gestel, T.; Doyen, W.; Leysen, R. A review of pressure-driven membrane processes in wastewater treatment and drinking water production. Environ. Prog. 2003, 22, 46-56. [CrossRef] 
26. Madaeni, S.S.; Fane, A.G.; Grohmann, G.S. Virus removal from water and wastewater using membranes. J. Membr. Sci. 1995, 102, 65-75. [CrossRef]

27. Meiramkulova, K.; Devrishov, D.; Zhumagulov, M.; Arystanova, S.; Karagoishin, Z.; Marzanova, S.; Kydyrbekova, A.; Mkilima, T.; Li, J. Performance of an Integrated Membrane Process with Electrochemical Pre-Treatment on Poultry Slaughterhouse Wastewater Purification. Membranes 2020, 10, 256. [CrossRef]

28. Chang, J.C.H.; Ossoff, S.F.; Lobe, D.C.; Dorfman, M.H.; Dumais, C.M.; Qualls, R.G.; Johnson, J.D. UV inactivation of pathogenic and indicator microorganisms. Appl. Environ. Microbiol. 1985, 49, 1361-1365. [CrossRef] [PubMed]

29. Song, K.; Mohseni, M.; Taghipour, F. Application of ultraviolet light-emitting diodes (UV-LEDs) for water disinfection: A review. Water Res. 2016, 94, 341-349. [CrossRef] [PubMed]

30. Cutler, T.D.; Zimmerman, J.J. Ultraviolet irradiation and the mechanisms underlying its inactivation of infectious agents. Anim. Heal. Res. Rev. 2011, 12, 15-23. [CrossRef]

31. Gray, N.F. Ultraviolet Disinfection. In Microbiology of Waterborne Diseases; Elsevier: Amsterdam, The Netherlands, 2014; pp. 617-630, ISBN 9780124158467.

32. Giese, N.; Darby, J. Sensitivity of microorganisms to different wavelengths of UV light: Implications on modeling of medium pressure UV systems. Water Res. 2000, 34, 4007-4013. [CrossRef]

33. American Water Works Association; Water Environment Federation; American Public Health Association. Membrane Filter Techniques. In Standard Methods for the Examination of Water and Wastewater; Amer Public Health: Washington, DC, USA, 1998; ISBN 0-87553-235-7.

34. APHA; AWWA; WEF. Standard Methods for Examination of Water and Wastewateri, 22nd ed.; American Public Health Association: Washington, DC, USA, 2012; ISBN 978-0875532356.

35. Meiramkulova, K.; Orynbekov, D.; Saspugayeva, G.; Aubakirova, K.; Arystanova, S.; Kydyrbekova, A.; Tashenov, E.; Nurlan, K.; Mkilima, T. The Effect of Mixing Ratios on the Performance of an Integrated Poultry Slaughterhouse Wastewater Treatment Plant for a Recyclable High-Quality Effluent. Sustainability 2020, 12, 6097. [CrossRef]

36. Huang, X.; Qu, Y.; Cid, C.A.; Finke, C.; Hoffmann, M.R.; Lim, K.; Jiang, S.C. Electrochemical disinfection of toilet wastewater using wastewater electrolysis cell. Water Res. 2016, 92, 164-172. [CrossRef] [PubMed]

37. Cordier, C.; Stavrakakis, C.; Morga, B.; Degrémont, L.; Voulgaris, A.; Bacchi, A.; Sauvade, P.; Coelho, F.; Moulin, P. Removal of pathogens by ultrafiltration from sea water. Environ. Int. 2020, 142, 105809. [CrossRef]

38. De Battisti, A.; Formaglio, P.; Ferro, S.; Al Aukidy, M.; Verlicchi, P. Electrochemical disinfection of groundwater for civil use-An example of an effective endogenous advanced oxidation process. Chemosphere 2018, 207, 101-109. [CrossRef]

39. Whiteley, M.; Bangera, M.G.; Bumgarner, R.E.; Parsek, M.R.; Teitzel, G.M.; Lory, S.; Greenberg, E.P. Gene expression in Pseudomonas aeruginosa biofilms. Nature 2001, 413, 860-864. [CrossRef]

40. Drenkard, E. Antimicrobial resistance of Pseudomonas aeruginosa biofilms. Microbes Infect. 2003, 5, 1213-1219. [CrossRef]

41. Mah, T.-F.; Pitts, B.; Pellock, B.; Walker, G.C.; Stewart, P.S.; O’Toole, G.A. A genetic basis for Pseudomonas aeruginosa biofilm antibiotic resistance. Nature 2003, 426, 306-310. [CrossRef] [PubMed]

42. Kisk, G.; Szab, O. Biofilm removal of Pseudomonas strains using hot water sanitation. Acta Univ. Sapientiae Aliment. 2011, 4, 69-79.

43. Cornejo-Juárez, P.; Vilar-Compte, D.; Pérez-Jiménez, C.; Ñamendys-Silva, S.A.; Sandoval-Hernández, S.; Volkow-Fernández, P. The impact of hospital-acquired infections with multidrug-resistant bacteria in an oncology intensive care unit. Int. J. Infect. Dis. 2015, 31, 31-34. [CrossRef]

44. Shelobolina, E.S.; Walker, D.K.; Parker, A.E.; Lust, D.V.; Schultz, J.M.; Dickerman, G.E. Inactivation of Pseudomonas aeruginosa biofilms formed under high shear stress on various hydrophilic and hydrophobic surfaces by a continuous flow of ozonated water. Biofouling 2018, 34, 826-834. [CrossRef] [PubMed]

45. Høiby, N.; Bjarnsholt, T.; Givskov, M.; Molin, S.; Ciofu, O. Antibiotic resistance of bacterial biofilms. Int. J. Antimicrob. Agents 2010, 35, 322-332. [CrossRef] [PubMed] 